\title{
A Comparative Study of Eastern and Western Music Aesthetics from the Perspective of Cross-culture
}

\author{
Hu Ping ${ }^{1}$
}

${ }^{1}$ Jianghan University, Wuhan, Hubei 430056

hp@jhun.edu.cn

\begin{abstract}
Cross-cultural comparison and dialogue is a new way of mutual exchange, mutual reference, and joint development of Eastern and Western music cultures in the world, serving as an important prerequisite for the development of various musical cultures in China. This paper makes a comparative analysis of the commonness and differences between Eastern and Western music aesthetics from the perspective of cross-culture. Firstly, the aesthetic connotation of Eastern and Western music is expounded. Secondly, the commonness of Eastern and Western music aesthetics is analyzed from two aspects: the expression mode of aesthetic characteristics and the aesthetic cultural characteristics of music. Finally, the differences of Eastern and Western music aesthetics are analyzed from three aspects: aesthetic characteristics, aesthetic orientation, and aesthetic methods of music.
\end{abstract}

Keywords: Cross-culture; Music aesthetics; Comparative study

\section{跨文化视角下的东西方音乐审美比较研究}

\author{
胡萍 1
}

\author{
${ }^{1}$ 江汉大学音乐学院 湖北 武汉 430056 \\ 37260994@qq.com
}

\section{摘要}

跨文化比较与对话，是当今世界东西方音乐文化相互交流、相互借鉴、共同发展的新途径，更是我国发展各类 音乐文化的重要前提。本文以跨文化为视角, 对东西方音乐审美的共性与差异进行对比分析。首先对东西方音 乐的审美内涵进行阐述，其次从美感特征表现方式与音乐审美文化特征两个方面对东西方音乐审美的共性进 行分析，最后从音乐的美感特征、审美取向以及审美方式三个方面分析东西方音乐审美的差异性。

关键词：跨文化；音乐审美；比较研究

\section{1. 前言}

在全球一体化发展进程中, 文化的差异性普遍存 在, 多元文化为全球音乐艺术的发展提供了新的视角 与机遇, 打破东西文化的二元对立思维, 消除文化中 心主义的束缚。以平等与尊重的态度看待东西方音乐 的共性与差异, 已经成为世界音乐艺术发展的大势所 趋。从跨文化角度对东西方音乐审美进行比较与研究, 一方面能够实现对东西方音乐文化的准确认知, 提供 了解东西方音乐文化的契机; 另一方面能够为东西方 音乐的融合找到合理的切入点与途径, 也为中国音乐
艺术的发展提供新的思路与资源。

\section{2. 东西方音乐的审美内涵阐述}

\section{1 东方音乐的审美内涵}

广义上的东方音乐包括日本音乐、印度音乐、土 耳其音乐、伊朗音乐、阿拉伯地区音乐等多种音乐类 型。虽然地域多样性显著, 但整体性特点也十分突出 [1]。由于中国是东方大国, 并对日本、印度等地区音 乐影响深远, 因此, 本文以中国音乐为东方音乐的主 体, 从与西方音乐的共性和差异角度进行东西方音乐 
审美比较研究。

东方音乐以 “中和” 为美, 追求幽远、空灵的精 神境界以及弦外之音的艺术表达, 以音乐意境传达审 美主体的内心世界，不对外部世界做过多的模仿，注 重 “我”与 “物” 之间的关系, 以 “意” 为音乐表达 的核心内涵。因此，东方音乐具有虚中见实的美感特 征、以我观物的审美取向以及物感心动的审美方式。

\section{2 西方音乐审美内涵}

广义上的西方音乐包括古罗马时期至新世纪音 乐时期八个阶段的音乐, 时间跨度五千余年 ${ }^{[2]}$ 。狭义 的西方音乐包括欧洲十六世纪的巴洛克时期音乐、十 八世纪的古典主义时期音乐、十九世纪的浪漫主义时 期音乐以及现代音乐和新世纪音乐, 本文所探讨的西 方音乐为狭义西方音乐。

西方音乐以 “规律” 为美, 追求对外部世界的模 仿与再现, 以此探寻对世界本质的认识, 注重 “物” 与 “物”之间的关系, 以 “形” 为音乐表达的核心内 涵, 通过音乐对 “形” 的模仿引出欣赏者的 “情”, 再以 “情” 的抒发引出欣赏者对 “理” 的思考与认 知。因此, 西方音乐具有求真重理的美感特征、以物 观物的审美取向以及重形求实的审美方式。

\section{3. 东西方音乐的审美比较分析}

\section{1 东西方音乐的审美共性分析}

\section{1. 美感特征表现方式的共性}

在东西方音乐作品中, 通常以节奏的力度和深度 来表现音乐的美感特征。并且, 通过力度和深度的逐 步减弱或节奏的调整, 达到平缓柔和的音乐情感表达 效果 ${ }^{[3]}$ 。例如中国的琵琶武曲《十面埋伏》, 与琵琶文 曲的抒情高雅、轻柔平稳不同, 《十面埋伏》运用琵琶 演奏中的扫拂技巧, 通过力度大、节奏强的弹奏方式 表现出紧迫的音乐氛围, 特别是该曲目的核心部分, 以复杂多变的琵琶 “夹扫” , 表现出战场疾风骤雨般 的变幻。

在西方的音乐作品中, 德国音乐家贝多芬的《降 $\mathrm{E}$ 大调第三交响曲》的第一乐章也是通过力度和节奏 感非常强的重音演奏方式, 从不协和音到切分节奏再 到阔大音域, 展现出史诗般的战斗场面, 突显出描绘 对象一一英雄的坚毅、勇敢以及困惑和痛苦, 具有高 度的戏剧效果。

从这两部音乐作品的节奏和演奏力度上观察比 较, 东西方音乐在表达感情色彩强烈的乐曲主题内容 时, 均是通过增强音乐表现的深度和强度的方式来达 到表达音乐内涵与美感特征的效果。

\section{2. 音乐审美文化特征的共性}

从东西方音乐美学思想的演进历程来看, 两者都 经历了漫长的发展过程, 宗教、哲学与文化对其发展
影响深刻, 在音乐审美文化特征上都表现出丰富性 ${ }^{[4]}$ 。 东方音乐审美文化受儒道思想影响深远，儒家思想关 注音乐与社会的关系, 重视音乐的教化功能, 强调以 礼制乐; 道家思想关注音乐与自然的关系，重视音乐 的天然性, 强调 “法天贵真”。儒、道两家思想虽不 同, 甚至对立, 但经过长期发展与融合, 最终在音乐 中呈现出儒道互补的状态。例如中国的古筝曲《汉宫 秋月》, 以平稳、简洁的吟、滑、按等多种古筝弹奏手 法, 刻画出宫女的惆怅与苦闪。其中, 重意轻声为道 家思想的体现，而由宫女的惆怅与苦闪所引起的同情、 怜悯则体现出儒家的伦理观念。

在西方音乐中, 古希腊神话是古希腊音乐的源泉, 虽然古希腊音乐已经消失, 但古希腊神话对西方音乐 的影响依然延续至今。直至近代, 希腊神话中的人物 仍然出现在音乐作品中。例如法国作曲家德彪西的 《牧神的午后前奏曲》, 以平缓从容的长笛描绘古希 腊神话中的牧神一一潘在树林中醒来, 追忆刚刚消失 的梦境, 一副慵懒、缱绻的场景。除古希腊神话外, 基督教在西方音乐中也具有极为重要的地位, 音乐作 品中经常出现宗教元素或直接以赞美上帝为主题 ${ }^{[5]}$ 。 例如贝多芬的 《欢乐颂》, 以低音的大提琴开始, 逐渐 扩大至整个乐队, 节奏和力度由弱到强, 犹如洪流之 势, 形成一种强大的感化人的力量, 营造出庄严肃穆 的宗教氛围，体现出基督教的博爱思想。

由此可见, 东西方音乐在美学发展上并非只受一 种文化或一类思想影响, 音乐审美文化特征均呈现出 丰富性。

\section{2 东西方音乐的审美差异性分析}

\section{1. 音乐美感特征差异}

由于文化背景与哲学思想的差异, 东西方音乐在 美感特征上也存在明显不同。东方音乐哀而不伤、怨 而不怒、中正温和，讲究 “冲淡之美” 以及 “天人合 一” 的境界; 西方音乐则直白激烈、辉煌宏大, 崇尚 理性、求真务实，关注自我认知与净化。

\section{（1）虚中见实一一东方音乐的美感特征}

东方音乐艺术创作包含着 “无中生有” “虚实 相生” “动静相易” 的意境追求与哲理, 在音乐中探 求 “无”与 “有” 的统一、“虚”与 “实” 的结合以 及 “动” 与 “静” 的变幻。即便面对一个实在的音乐 创作主题, 东方音乐也会通过旋律的变化表现出空灵 的意境, 运用声外之韵、弦外之音, 将自然界的静㨫 空灵之境与欣赏者的幽思之感相连, 从而呈现出宁静、 和谐的美感特征。例如中国古琴曲《梅花三弄》, 乐曲 由引子、静态部分、动态部分以及尾声组成。其中, 引子音调优美、节奏舒缓, 呈现出清幽的意境, 与其 后的三个部分形成对比。静态部分以轻快的泛音弹奏 与有力的附点弹奏为乐曲增添高雅庄重的音乐色彩, 表现出梅花的恬静与端庄 ${ }^{[6]}$ 。动态部分通过节奏的变 化呈现出狂风大作、雨雪交加的音乐氛围, 以跌宕起 
伏的旋律、刚健强劲的节奏刻画出梅花坚毅不屈、高 洁孤傲的品质。这种一静一动的节奏变幻, 使梅花傲 雪凌霜的品格从虚幻的音乐空间中显现出来, 体现出 虚中见实的东方音乐美感特征。

（2）求真重理一一西方音乐的美感特征

与东方音乐消解 “理念” 、展现 “虚无” 不同, 西方音乐受科学与理性的影响, 注重制造 “理念”, 突出 “实在”, 倾向于在音乐中灌输一种强烈的情感 与鲜明的观念, 总体音乐感受是清晰的、统一的, 注 重追求音乐的真实性与意义的实在性。例如贝多芬的 《C 小调第五交响曲》, 该乐曲共四个乐章, 第一乐章 便以四个强有力的音符重重地击打欣赏者的心灵, 简 短却震撼, 如同 “命运的吒门” ; 第二乐章舒缓、平 稳; 第三乐章旋律忽升忽降, 仿佛与命运的再次抗争; 第四章节奏轻快、活泼, 如同胜利后的狂欢, 整个乐 曲鲜明地体现出人与命运的对抗与斗争。

同样是以力度和深度的变化表现音乐的美感, 但 《C 小调第五交响曲》与《梅花三弄》重视内心感受、 注重物我相融不同, 《C 小调第五交响曲》重视思维与 理智, 关注人与自然、与命运的抗争 ${ }^{[7]}$ 。可见, 在音 乐美感特征的表现上, 东方音乐强调自然美、社会美 以及人情美; 西方音乐则强调音乐本体的理性美, 忽 略本体之外的自然、社会之美。

\section{2. 音乐审美取向差异}

音乐审美取向是音乐审美活动中, 审美主体对客 体的选择与价值判断。东西方音乐审美取向的差异代 表着两者对音乐之美的探索方向与审美趣味的差异, 东方音乐以我观物, 重视物我统一的美; 西方音乐以 物观物, 重视物我分立的美, 这种统一与分立的审美 倾向造成了东西方音乐在审美取向上的差异。

\section{（1）以我观物一一东方音乐的审美取向}

东方音乐重视诗意的表达, 追求音乐折射出的人 格力量与人性光辉, 通过弦外之音间接反映生活或者 超越现实, 强调 “善” 与 “美” 的和谐统一。音乐织 体思维单向度延伸、蜿蜒起伏, 以横向旋律为基础, 呈现出单线上下游动的效果, 追求乐器音色幽静深远、 虚淡空灵。因此, 从对乐器的使用情况来看, 东方乐 器崇尚个性, 注重乐器个体的特殊性与穿透性。例如 中国的传统乐器编钟、古筝、三弦琴、二胡、琵琶等, 每一类乐器都具有自身独特的音质, 因此乐器之间难 以配合, 无法成为综合交叉的网状音乐织体, 造成东 方音乐在审美取向上刻意避免立体化的音响效果 ${ }^{[8]}$ 。 东方音乐并未抽象化, 因此乐器音色接近人声, 始终 保持着感性的生命体验, 与具体的、直接的生活相联 系, 音乐中蕴含着生命的律动, 能够唤起欣赏者的情 感共鸣, 与音乐的生命状态相通, 从而进入以我观物 的精神境界。

\section{（2）以物观物一一西方音乐的审美取向}

西方音乐重视哲学的概括, 追求音乐的逻辑性与
动机, 具有较强的戏剧性特点, 通过音乐的凝练与情 感的激荡直面自然界与人生, 强调对 “真” 的追求。 音乐织体思维纵横交错、网状排列, 以和声为基础, 构建出纵横交织、丰满厚重的立体音响效果, 追求对 欣赏者的震撼与感召。因此, 从对乐器的使用情况来 看, 西方乐器追求共性, 注重乐器之间的融合性与渗 透性。例如大提琴、小提琴、钢琴、长号、长笛等, 虽然在音量、音色等方面具有差异, 但都能够相互配 合, 形成绵密、丰富的和声。因此, 西方音乐少有独 奏, 多为协奏曲、交响乐或奏鸣曲。并且, 乐器音色 远离人声，接近 “器声” , 即 “一种非自然的, 人为 造成的物具。这种物具具有这样的特点, 它不同于任 何一种具体的物具, 但又能够与任何物体的音色相融 合。” ${ }^{[9]}$ 与东方乐器相比, 音质上摆脱了个性的束缚, 更具理性与抽象性，使西方音乐抽象成为一个开放的 逻辑体系, 但却失去了对生命的内在体验与感悟。

\section{3. 音乐审美方式差异}

东西方音乐在审美方式上各具特色，东方音乐审 美方式讲究体悟, 使欣赏者在审美活动中认识自己、 提升自己，达到物我合一、物感心动的境界; 西方音 乐审美方式突出认识, 使欣赏者在审美活动中突破自 身的局限, 净化自己, 获得崇高的审美感受。

\section{（1）物感心动一一东方音乐的审美方式}

在漫长的发展历程中, 东方音乐逐渐形成了自己 的意义表达体系以及审美感知方式, 这种体味、顿悟 的审美感知方式对音乐中的 “留白” 与弦外之音的 感知能力要求较高。中国古典音乐多以自然山水为题, 但很少对其进行直接描绘与模仿, 而是以含蓄、内玫 的手法着重表现 “弦外之音”。例如中国乐曲《渔歌》, 该乐曲没有通过旋律直接表现出水波与船的形态, 而 是运用平和、舒缓的旋律抒发 “远离人世烦恼的潇酒 自由之情” ${ }^{[10]}$, 使欣赏者从这一弦外之音体会到生活 意趣与哲学之思。正如唐代诗人张九龄诗中所言 “岂 是声能感, 人心自不平”，欣赏者的 “心不平” 不仅 在于音乐本体, 更在于自身的审美经验。因此, 东方 音乐的审美方式不仅是对乐曲的直接感性感受, 更是 超越音乐内涵的韵外之思与心灵体悟。

\section{（2）重形求实一一西方音乐的审美方式}

西方音乐审美目标在于认清对象的意义, 因此审 美方式倾向于认识与定义。以情感体验为前提, 欣赏 者不仅需要把握音乐的力度、和声、节奏等艺术表现 规律, 还须融入欣赏者的理性判断、联想以及想象。 西方音乐善于直接表现与刻画描绘对象, “日出” 是 西方音乐中经常出现的主题, 常以低音和长音表现日 出前的黑夜, 给欣赏者带来昏暗、缓慢的听觉联想。 再用管弦乐舒缓、温和的节奏营造出黎明时刻的宁静, 最后使用高音与明朗的旋律描绘出光线喷薄而出的 情景, 使欣赏者产生世界充满光明的联想 ${ }^{[11]}$ 。例如美 国作曲家格罗菲的《大峡谷组曲》, 该乐曲的 “日出” 乐章正是运用相同的手法表现出日出前的黑暗、黎明 以及日出的情景, 使欣赏者产生万物复苏、世界光明 
的激昂情绪。与中国乐曲《渔歌》的弦外之音、韵外 之思不同, 《大峡谷组曲》重视对情景的直接描绘以及 欣赏者的知性联想, 最终目的在于准确把握音乐音响 与日出景象的对应关系。

\section{4. 结语}

综上所述，东西方音乐审美既有共性也有差异性， 在美感特征表现方式上，东西方音乐都以增强音乐表 现的深度和力度来表达强烈的感情色彩; 在审美文化 特征上, 东西方音乐都并非只受一种文化的影响, 具 有丰富的文化性特点。而在音乐美感特征上, 东方音 乐虚中见实, 西方音乐求真重理; 在音乐审美取向上, 东方音乐以我观物, 西方音乐以物观物; 在音乐审美 方式上, 东方音乐重视物感心动, 西方音乐则重形求 实。通过两者共性与差异的对比分析, 能够把握东西 方音乐的个性与共性, 从而为两者的优化与相互借鉴 奠定基础。

\section{项目基金}

教育部人文社会科学研究青年基金项目资助（项目名 称: 文化融合视野下当代室内乐“中国化”发展探究, 项目批准号: 19YJC760031)

\section{REFERENCES}

[1] He Haotian. New Trend of Chinese Pop Music: Integration of Chinese and Western Music Elements [J]. Chinese Culture Forum, 2016, No.119 (3): 155159.

[2] Guan Jianhua. Differences between Eastern and Western Music and Dialogue among Civilizations [J]. Music Art (Journal of Shanghai Conservatory of Music), 2014 (1): 80-92.

[3] Meng Zhan. Visualization of Music-The Influence of Music Score Form on the Development of Chinese and Western Music [J]. Music Creation, 2015 (2): 110-111.

[4] Qiu Guixiang. The Enlightment of Western Chinese Music Research to Chinese Western Music research [J]. Journal of Fujian Normal University: Philosophy and Social Sciences Edition, 2017 (3): 146-154.

[5] Sun Guozhong. Respect the Academic Tradition and Rethink the Research Path--Answer to Professor Ye Songrong on the Related Questions of "Western Music Research from the Perspective of China" [J]. Music Research, 2014 (3).

[6] Han Shalin, Yu Tao. Aesthetic Characteristics of Oriental Music [J]. Journal of Wuhan University of Technology (Social Science Edition), 2015 (4): 617 621.
[7] Bai Xuejun, Ma Xie, Tao Yun. Emotional Induction effect of Chinese-Western Music [J]. Journal of Psychology, 2016, 48 (7): 757-769.

[8] Ye Songrong. Viewing the "Chinese Vision" of Western Music Research from the "Externality" Theory and "Globalization Vision" [J]. Music Research, 2015 (4).

[9] Ye Songrong. Open Vision and Pluralistic Coexistence--Interpretation Path of Chinese Vision of Western Music Research [J]. Chinese Musicology, 2016, 4 (4): 116-126.

[10] Liu Chengji. Study on the Early Philosophy of Music in Chinese Society [J]. Seeking Truth, 2017 (5): 2 $+118-126$.

[11] Xue Zhong, Cao Guoliang. A Comparative Study of Ancient Chinese and Western "Music Imitation Theory" [J]. Music Creation, 2016 (5): 106-107. 